\title{
The Journal of Rheumatology
}

The Journal of Rheumatology

Volume 42, no. 11

The OMERACT Ultrasound Working Group 10 Years On: Update at OMERACT 12

George A. Bruyn, Esperanza Naredo, Annamaria lagnocco, Peter V. Balint, Marina Backhaus, Frederique Gandjbakhch, Marwin Gutierrez, Andrew Filer, Stephanie Finzel, Kei Ikeda, Gurjit S. Kaeley, Silvia Magni Manzoni, Sarah Ohrndorf, Carlos Pineda, Bethan Richards, Johannes Roth, Wolfgang A. Schmidt, Lene Terslev and Maria Antonietta D'Agostino

J Rheumatol 2015;42;2172-2176

http://www.jrheum.org/content/42/11/2172

1. Sign up for our monthly e-table of contents

http://www.jrheum.org/cgi/alerts/etoc

2. Information on Subscriptions

http://jrheum.com/subscribe.html

3. Have us contact your library about access options Refer_your_library@jrheum.com

4. Information on permissions/orders of reprints http://jrheum.com/reprints.html

The Journal of Rheumatology is a monthly international serial edited by Earl $D$.

Silverman featuring research articles on clinical subjects from scientists working in rheumatology and related fields. 


\title{
The OMERACT Ultrasound Working Group 10 Years On: Update at OMERACT 12
}

George A. Bruyn, Esperanza Naredo, Annamaria Iagnocco, Peter V. Balint, Marina Backhaus, Frederique Gandjbakhch, Marwin Gutierrez, Andrew Filer, Stephanie Finzel, Kei Ikeda, Gurjit S. Kaeley, Silvia Magni Manzoni, Sarah Ohrndorf, Carlos Pineda, Bethan Richards, Johannes Roth, Wolfgang A. Schmidt, Lene Terslev, and Maria Antonietta D'Agostino, on behalf of the OMERACT Ultrasound Task Force

\begin{abstract}
Musculoskeletal ultrasound (US) now thrives as an established imaging modality for the investigation and management of chronic inflammatory arthritis. We summarize here results of the Outcome Measures in Rheumatology (OMERACT) US working group (WG) projects of the last 2 years. These results were reported at the OMERACT 12 meeting at the plenary session and discussed during breakout sessions. Topics included standardization of US use in rheumatic disease over the last decade and its contribution to understanding musculoskeletal diseases. This is the first update report of WG activities in validating US as an outcome measure in musculoskeletal inflammatory and degenerative diseases, including pediatric arthritis, since the OMERACT 11 meeting. (First Release March 15 2015; J Rheumatol 2015;42:2172-6; doi:10.3899/jrheum.141462)
\end{abstract}

Key Indexing Terms: JOINT EROSIONS

As of 2015, musculoskeletal ultrasound (US) can no longer be considered as controversial in rheumatology; on the contrary, US thrives as an established imaging modality for the investigation and management of chronic inflammatory arthritis. Last year marked the 10-year jubilee of the OMERACT US working group (WG). Members of the WG met in Budapest, Hungary, for the OMERACT 12 conference, where results of the last 2 years of ongoing projects were presented. The several milestones reached in standardizing the use of US in rheumatic disease over the last decade and the contribution of US to understanding musculoskeletal diseases were highlighted in the plenary session and discussed during breakout sessions. This report provides an update on the activities of the WG in validating US as an outcome measure in musculoskeletal inflammatory and degenerative diseases including pediatric arthritis, since the last report on WG activities at OMERACT $11^{1}$.
From the Department of Rheumatology, MC Groep, Lelystad, The Netherlands; Department of Rheumatology, Hospital General Universitario Gregorio Marañón, Madrid, Spain; Department of Rheumatology, National Institute of Rheumatology and Rehabilitation, Budapest, Hungary; Department of Rheumatology, Sapienza Università di Roma, Rome, Italy; Rheumatology Research Group, The University of Birmingham, Birmingham, UK; Department of Internal Medicine 3 , University Clinic of Erlangen-Nuremberg, Erlangen, Germany; Clinica Reumatologica, Università Politecnica delle Marche, Jesi, Ancona, Italy; Service de Rhumatologie, Hôpital Pitié-Salpétrière, Paris, France; Department of Rheumatology, Copenhagen University Hospital at Glostrup, Copenhagen, Denmark; Department of Rheumatology, Instituto Nacional de Rehabilitacion, Mexico City, Mexico; Division of Rheumatology, University of Florida College of Medicine, Jacksonville, FL, USA; Department of Allergy and Clinical Immunology, Chiba University Hospital, Chiba, Japan; Pediatric Rheumatology Unit, IRCCS Ospedale Pediatrico Bambino Gesù, Rome, Italy; Institute of Rheumatology and Orthopaedics, Royal Prince Alfred Hospital, Camperdown, Australia; Division of Pediatric Rheumatology, Children's Hospital of Eastern Ontario, Ottawa, Canada; Medical Center for Rheumatology Berlin-Buch, Berlin; Charite University Hospital, Humboldt University, Berlin, Germany; Department of Rheumatology, Université Paris Ouest-Versailles-Saint Quentin en Yvelines, Hôpital Ambroise Paré, APHP, Boulogne-Billancourt, France.

G.A. Bruyn, MD, PhD, Department of Rheumatology, MC Groep, Lelystad; E. Naredo, MD, Department of Rheumatology, Hospital General

\begin{abstract}
Universitario Gregorio Marañón; P.V. Balint, $M D, P h D$, Department of Rheumatology, National Institute of Rheumatology and Rehabilitation; A. Iagnocco, MD, Department of Rheumatology, Sapienza Università di Roma; A. Filer, MD, PhD, Rheumatology Research Group, The University of Birmingham; S. Finzel, MD, Department of Internal Medicine 3, University Clinic of Erlangen-Nuremberg; M. Gutierrez, MD, Clinica Reumatologica, Università Politecnica delle Marche; F. Gandjbakhch, $M D$, Service de Rhumatologie, Hôpital Pitié-Salpétrière; L. Terslev, MD, Department of Rheumatology, Copenhagen University Hospital at Glostrup; C. Pineda, MD, Department of Rheumatology, Instituto Nacional de Rehabilitacion; G.S. Kaeley, MRCP, Division of Rheumatology, University of Florida College of Medicine; K. Ikeda, MD, PhD, Department of Allergy and Clinical Immunology, Chiba University Hospital; S. Magni Manzoni, MD, Pediatric Rheumatology Unit, IRCCS Ospedale Pediatrico Bambino Gesù; B. Richards, MD, Rheumatology Institute of Rheumatology and Orthopaedics, Royal Prince Alfred Hospital; J. Roth, MD, Division of Pediatric Rheumatology, Children's Hospital of Eastern Ontario; W.A. Schmidt, MD, PhD, Medical Center for Rheumatology Berlin-Buch; M. Backhaus, MD, PhD, Charite University Hospital, Humboldt University; S. Ohrndorf, MD, Charite University Hospital, Humboldt University; M.A. D'Agostino, MD, PhD, Department of Rheumatology, Université Paris Ouest-Versailles-Saint Quentin en Yvelines, Hôpital Ambroise Paré, APHP.

Address correspondence to Dr. G.A. Bruyn, Department of Rheumatology, MC Groep Hospitals, 8233 AA, Lelystad, The Netherlands.

E-mail: gawbruyn@wxs.nl
\end{abstract}




\section{A Decade Put into Historical Perspective}

At OMERACT 7 in 2004, a special interest group (SIG) dedicated to US was formed by a group of international rheumatologists with the aim of exploring the metric properties of musculoskeletal US. At this early stage, a systematic review of the musculoskeletal US literature in rheumatoid arthritis (RA) ${ }^{2}$ dissected the various gaps in existing knowledge, particularly underscoring the lack of US definitions of rheumatic pathology, instrument reliability, and instrument validity. Overall agreement was that because research resources of the SIG were limited, efforts had to be strictly prioritized. The very first publication of the group reported on a core set of practical US definitions for general rheumatic manifestations including synovitis, tenosynovitis, and erosions ${ }^{3}$. In considering which strategy to use, iterative exercises on synovitis in patients with RA were carried out from 2004 to 2010. These exercises involved US assessment of synovitis at both the patient level and the joint level $\mathrm{l}^{4,5,6,7}$. It was not surprising that the intra- and interexaminer $\kappa$ values for reading still images were better than for those of real-time image acquisition ${ }^{8}$.

By 2008, the perspective of developing an US disease activity score based on synovitis at the patient level loomed as a logical next step, i.e., a global synovitis score (GLOSS). Development of a GLOSS was the result of an iterative, gradual, slow-moving process, implicating a step-by-step approach that included several issues, e.g., the optimal number of joints, how to scan these (dorsal, volar), and B-mode alone or in combination with power Doppler. On the basis of favorable results of the preceding exercises ${ }^{4,5,6,7}$, an US-GLOSS, combining B-mode synovial hypertrophy and power Doppler in 1 score, was presented at OMERACT $10^{8}$. An additional advantage is that the GLOSS can be performed à la carte, i.e., in various joint number configurations. Subsequently, responsiveness of the GLOSS was tested in an international multicenter open-label medication trial evaluating responsiveness of power Doppler US in patients with RA with incomplete clinical response to methotrexate and treated with abatacept ${ }^{9}$. Preliminary results were reported at OMERACT $11^{10}$. During the group discussions and feedback sessions, a need for separate development of diagnostic and monitoring RA GLOSS systems was expressed. Currently, questions need to be addressed on which US findings are preferred for establishing a definite diagnosis (i.e., discrimination findings), and which findings are preferred for monitoring purposes, or for predicting/evaluating remission or flare for that matter. In addition, it is not yet clear how frequently US scans have to be repeated ${ }^{11}$. Two ongoing trials are assessing some of these aspects, namely, the TURA study (NTC 02056184), which is a longitudinal international randomized controlled trial (RCT) targeting remission, and the REVECHO study (NCT02140229), which is a longitudinal international RCT targeting the best strategy for maintaining longstanding remission.
As mentioned in the preceding report of OMERACT 11, testing the metric properties of US on tenosynovitis and tendon damage in patients with RA was another prioritized research area ${ }^{12,13,14,15}$. From a clinical point of view, tendon damage may be an important endpoint in RCT; it would also be clinically relevant to understand which US findings at joint and tendon level are able to predict tendon damage. Results of the tendon damage study in patients with RA showed good to excellent $\kappa$ values for intraobserver and interobserver reliability ${ }^{14}$. Additionally, an atlas of US images on tenosynovitis and tendon damage in RA was published as online material ${ }^{15}$.

\section{Current Research Agenda. "True Erosion," Gout, Pediatric Arthritis, OA, and Dactylitis}

During the workshop, the ongoing research agenda focused on additional data including the validation of US in RA erosions and in pediatric arthritis, as well as on new development of US as an outcome measure for other inflammatory rheumatic diseases, such as psoriatic arthritis (PsA) and gout. These topics were first presented in the plenary introduction and then discussed in the breakout sessions.

The first topic focused on the validation of US for detecting RA bone erosions. S. Finzel presented new findings on the prevalence of erosions versus normal cortical "breaks" in patients with RA and healthy controls, using high-resolution peripheral quantitative computed tomography as the gold standard. The rationale of these studies is to get a better idea of what a "true US erosion" represents. Subsequently, the intraobserver and interobserver reliability of US detecting these structures was tested in patients with RA and healthy controls by 12 rheumatologists expert in US (Table 1). Based on the outcome of this study, further studies are planned to define an US-detected RA erosion and the minimal size that can be accurately detected.

Next, a presentation by L. Terslev provided insights into how US can assess the 3 key domains in gout, i.e., inflammation, damage, and urate load ${ }^{16}$. By using a previous systematic literature review, 4 elementary US components were identified, i.e., double contour sign, aggregates, tophi, and erosion ${ }^{17}$. The US definitions of these 4 identified lesions were agreed upon by the group using a Delphi exercise ${ }^{18}$. Subsequently, the metric properties of these components were

Table 1. US testing intraobserver and interobserver reliability on small erosions in patients with RA and healthy controls.

\begin{tabular}{lcccc}
\hline & \multicolumn{2}{c}{ Intraobserver } & \multicolumn{2}{c}{ Interobserver } \\
& $\begin{array}{c}\text { Normal } \\
\text { Break }\end{array}$ & $\begin{array}{c}\text { Abnormal } \\
\text { Break }\end{array}$ & $\begin{array}{c}\text { Normal } \\
\text { Break }\end{array}$ & $\begin{array}{c}\text { Abnormal } \\
\text { Break }\end{array}$ \\
\hline Palmar long & $0.1-0.8$ & $0.6-0.9$ & 0.8 & 0.9 \\
Dorsal long & $0.4-0.6$ & $-0.1-0.5$ & 0.4 & 0.7 \\
Palmar transv & $0.2-0.7$ & $0.5-0.7$ & 0.7 & 0.5 \\
Dorsal transv & $0.3-0.9$ & $0.4-0.8$ & 0.3 & 0.4 \\
\hline
\end{tabular}

US: ultrasound; RA: rheumatoid arthritis. 
assessed in a patient reliability study conducted in Berlin, December 2013. Preliminary results were presented, showing acceptable intraobserver reliability for detecting and acquiring images of double contour, tophi, and erosions, but not for aggregates. Interobserver $\kappa$ values were even lower ${ }^{16}$. On the basis of the reliability results, overall agreement was that further validation was needed for double contour sign and aggregates.

A. Iagnocco presented work conducted in hand osteoarthritis (OA). Results of a reliability study focusing on cartilage damage showed intrarater and interrater $\kappa$ of 0.52 and 0.80 using dichotomous scoring ${ }^{19}$. A second reliability exercise was aimed at evaluating the possibility to grade together structural damage in hand $\mathrm{OA}$, by using a semiquantitative grading of both cartilage and osteophyte lesions. This study showed good results for osteophyte scoring, but moderate for cartilage ${ }^{20}$. Overall agreement was that an US core domain set to be used in hand OA structural lesions should include cartilage scoring in a dichotomous way and osteophyte scoring on a semiquantitative scale (0-3).

J. Roth presented the latest concepts of how US can be used as an instrument for assessment of pediatric pathology. A core domain set for pediatric pathology has yet to be determined. The US definitions of joints of healthy children have recently been published ${ }^{21}$. The next step is to define synovitis in children with juvenile idiopathic arthritis (JIA), which shall be done by consensus through consecutive Delphi rounds. The main objective of the pediatric Delphi process is to obtain consensus on the B-mode and Doppler US elementary components to include in the definition of synovitis in children. The secondary objective is to obtain consensus on the type of scoring system that will be developed. Both the synovitis definition and the scoring system will subsequently be tested in future US exercises in children with JIA.

The last topic was dactylitis, presented by G. Kaeley. He explained that dactylitis was identified as part of a domain core set for PsA. US candidate elementary components have been identified through a literature review ${ }^{22}$. A Delphi process is under way to reach consensus on the initial set of elements that warrant study. Based on the results of the first round, the candidate elements were prioritized (Figure 1). A second round of the Delphi process is being conducted to plan a reliability exercise looking at evaluating the identified elementary lesions.

Following these presentations, each subgroup was divided into smaller discussion groups (about 15 participants each, including 2 patient partners), who were then asked to consider a set of 4 draft questions based on endorsement of the work done and the future research agenda of the group by OMERACT participants (Table 2). Draft questions pertained to construct validity of hand $\mathrm{OA}$, a core domain set of US to be used in gout patients, a core domain set to be used in patients with PsA, and lastly, future research in RA erosions. Each discussion group then reported its main points to all participants at the end of the breakout sessions.

Following this report, the questions were voted on for

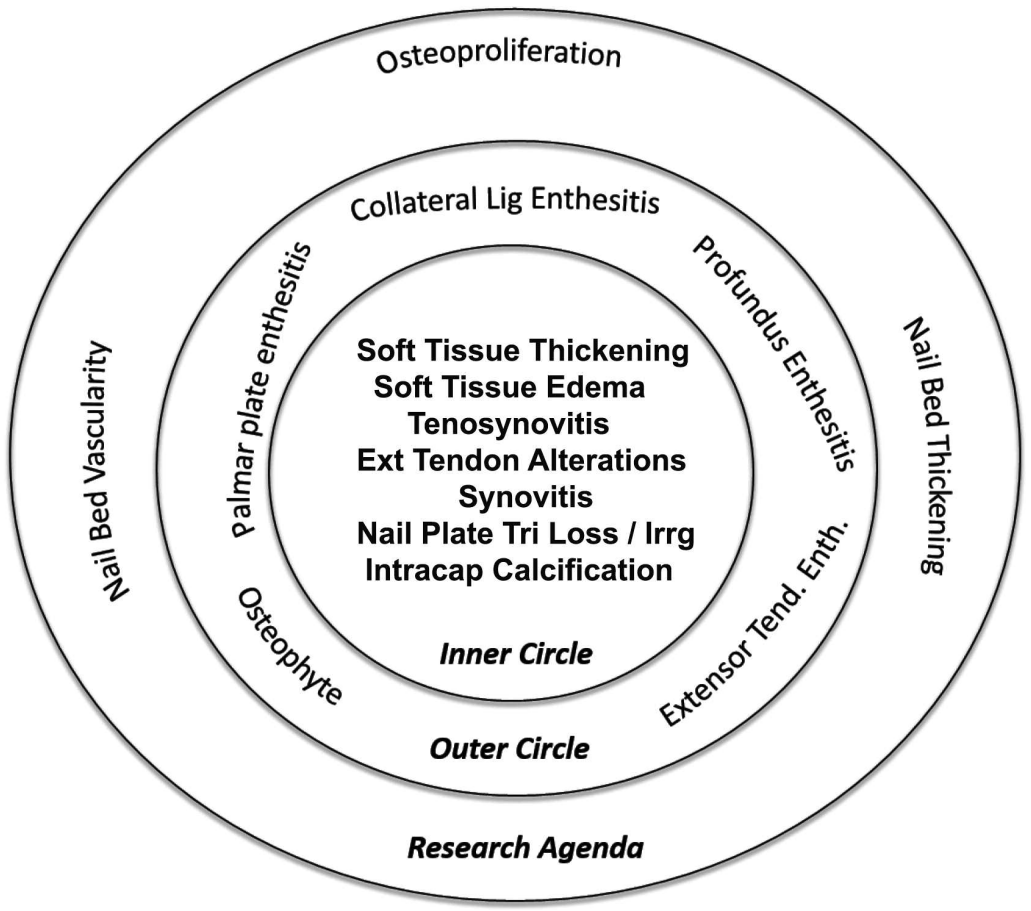

Figure 1. Categorization of candidate elements in dactylitis into domains after first round of Delphi process. Nail plate Tri Loss / Irrg: loss of nail plate trilaminar structure and/or irregularity of nail plate; Intracap calcification: intracapsular calcification; Lig: ligament; Tend.: tendon; Enth.: enthesitis. 
Table 2. Endorsement of 4 voting questions in the final plenary session.

Voting Question

Endorsement, \%

Do you agree to investigate the correlation between

structural damage and inflammation and clinical

outcomes in hand OA?

81

Do you agree that US can be developed as an

outcome instrument in dactylitis?

Do you agree that an ultrasound domain core set in gout

should include urate load, inflammation, and damage?

Following successful work on synovitis and tenosynovitis

in RA, should we continue to work on erosions?
77

76

76
OA: osteoarthritis; US: ultrasound; RA: rheumatoid arthritis.

potential endorsement by all conference participants at the final plenary session on the last day of the conference. The topics proposed in the formulated questions were endorsed by a strong majority of attendees.

Below, the main points of discussion are reported. Regarding the US detection of erosions, there was wide-spread recognition of the importance of developing an US validated measure of erosions, since this tool is widely introduced in the evaluation of RA synovitis. Participants agreed that the evaluation of erosions by US would provide valuable support for early detection of erosive disease. In addition, the higher sensitivity of US for detecting erosions compared to radiography, owing to its better resolution and to the tomographic nature of the technique, is considered an added value. The detection of erosions in early inflammatory disease was felt to be a priority research area and an objective to be tested in future clinical trials. However, additional validation was required before proposing US as a standard outcome measurement of structural damage. For example, more data on the discriminative capability of US for distinguishing between normal cortical breaks and small erosions is needed. One breakout group pointed out the need for additional RCT supporting the responsiveness of inflammatory findings, such as synovitis, before moving to structural damage. Nevertheless, general agreement was expressed on the potential interest of this tool in evaluating erosions.

There was also strong agreement that US is a valuable tool for evaluation of patients with gout. Based on discussions in the breakout groups, several key points were raised by participants, especially as related to the role of US in gout. The importance of US in evaluating urate load was underscored. Participants agreed on the valuable role of US in distinguishing and measuring acute and chronic gout and in identifying core domains for both stages of disease (tophi, synovial inflammation, aggregates, and urate deposits). However, there remains a lack of clear definitions of elementary lesions detected by US. Therefore, discussions were mostly related to which lesions should be assessed by US and which definitions should be used. The discriminative ability of US gout lesions in comparison to other arthropathies has been suggested as a priority for validation.
The third question, based on the development of US in PsA, also received agreement from the majority of participants. In each breakout group in which this topic was discussed, unanimous concordance on the need to pursue standardization of US for management of PsA was reached. The value of US in the evaluation of PSA synovitis was recognized and supported, as well as the potential value of US in the evaluation of dactylitis. The development of US as a responsive tool for following this clinical manifestation was unanimously supported. Finally, the potential development of a structural US score in hand OA was discussed. On the basis of the work already performed by the WG in terms of inflammatory abnormalities, agreement was obtained that the future research agenda should focus on correlations between structural and inflammatory lesions and clinical outcomes in symptomatic hand OA.

The objectives of this workshop were to present both the existing knowledge on the use of US in areas that have been explored over the last decade and to decide priorities for future research. US is a unique outcome measure that reveals both the past and present status of various rheumatic diseases. Considerable progress has been reported in different areas, including synovitis and structural damage in RA, tenosynovitis in RA, and structural damage in hand OA. At this stage it is not possible to predict the influence of the workshop's success in these areas, but the effects may be far-reaching, both for daily practice and clinical research. Examples of the aspect of daily practice may be other treatment expectations or less use of radiographic radiation; an example of the clinical research aspect may be novel insights into pathogenetic mechanisms, e.g., in OA.

Here follows the research agenda drafted to address existing gaps in our knowledge regarding work to be done in hand OA, gout, PsA, and erosions (Table 3):

- To investigate the construct validity of US assessment of hand OA as compared to clinical manifestations of the disease

- To assess the metric properties of US in other OA joints (e.g., the knee)

- To further define the basic abnormalities evaluable with US in gout and to test the reliability, responsiveness, and discriminant capacity of these lesions

- To further identify and define the basic US abnormalities that can be included in the US assessment of PsA and to test their metric properties

- To further address the concurrent validity and sensitivity to change of US-detected early bone erosions

- To develop definitions for joint inflammatory pathology in childhood

Other areas of future research include systemic vasculitis, synovial biopsy, and knee OA. Over the next 2 years, fresh data will be reported on the different topics of the research agenda. 
Table 3. Future research agenda and time line of the OMERACT US working group.

\begin{tabular}{|c|c|c|}
\hline US Research Field & Outcome & Research Phase \\
\hline $\begin{array}{l}\text { Detection of minimal } \\
\text { erosions in RA }\end{array}$ & Minimal erosion & Validity studies \\
\hline $\begin{array}{l}\text { Definition of an US } \\
\text { core domain set in } \\
\text { gout }\end{array}$ & $\begin{array}{c}\text { Inflammation, damage, } \\
\text { urate load }\end{array}$ & $\begin{array}{c}\text { Delphi study on } \\
\text { definitions/reliability }\end{array}$ \\
\hline $\begin{array}{l}\text { Definition of an US } \\
\text { core domain set in hand } \\
\text { OA }\end{array}$ & Structural lesions & Delphi study/reliability \\
\hline $\begin{array}{l}\text { Definition of an US core } \\
\text { domain set in PsA }\end{array}$ & Dactylitis & Delphi study \\
\hline $\begin{array}{l}\text { Definition of an US } \\
\text { core domain set in } \\
\text { pediatric arthritis }\end{array}$ & Synovitis & $\begin{array}{l}\text { Delphi study on } \\
\text { normal sonoanatomy } \\
\text { and synovitis }\end{array}$ \\
\hline
\end{tabular}

US: ultrasonography; RA: rheumatoid arthritis; OA: osteoarthritis; PsA: psoriatic arthritis.

\section{APPENDIX}

List of study collaborators: OMERACT Ultrasound Task Force: Philippe Aegerter, Sibel Aydin, Marina Backhaus, David Bong, Isabelle Chary-Valckenaere, Paz Collado, Eugenio De Miguel, Christian Dejaco, Oscar Epis, Jane E. Freeston, Frederique Gandjbakhch, Walter Grassi, Petra Hanova, Sandrine Jousse-Joulin, Fredrick Joshua, Juhani Koski, Damien Loeuille, Ingrid Möller, Viviana Ravagnani, Anthony Reginato, Veronica Sharp, Nanno Swen, Marcin Szkudlarek, Richard J. Wakefield, and Hans-Rudolf Ziswiler.

\section{REFERENCES}

1. Iagnocco A, Naredo E, Wakefield R, Bruyn GA, Collado P, Jousse-Joulin S, et al. Responsiveness in rheumatoid arthritis. A report from the OMERACT 11 ultrasound workshop. J Rheumatol 2014;41:379-82.

2. Joshua F, Lassere M, Bruyn GA, Szkudlarek M, Naredo E, Schmidt WA, et al. Summary findings of a systematic review of the ultrasound assessment of synovitis. J Rheumatol 2007;34:839-47.

3. Wakefield R, Balint PV, Szkudlarek M, Filippucci E, Backhaus M, D’Agostino MA, et al. Musculoskeletal ultrasound including definitions for ultrasonographic pathology. J Rheumatol 2005;32:2485-7.

4. Naredo E, Möller I, Moragues C, de Agustin JJ, Scheel AK, Grassi $\mathrm{W}$, et al. Interobserver reliability in musculoskeletal ultrasonography: results from a "Teach the Teachers" rheumatologist course. Ann Rheum Dis 2006;65:14-9.

5. Scheel AK, Schmidt WA, Hermann KG, Bruyn GA, D’Agostino MA, Grassi W, et al. Interobserver reliability of rheumatologists performing musculoskeletal ultrasonography: results from a EULAR Train the trainers course. Ann Rheum Dis 2005;64:1043-9.

6. Bruyn GA, Pineda C, Hernandez-Diaz C, Ventura-Rios L, Moya C, Garrido J, et al. Validity of ultrasonography and measures of adult shoulder function and reliability of ultrasonography in detecting shoulder synovitis in patients with rheumatoid arthritis using magnetic resonance imaging as a gold standard. Arthritis Care Res 2010;62:1079-86.

7. Bruyn GA, Naredo E, Möller I, Moragues C, Garrido J, de Bock $\mathrm{GH}$, et al. Reliability of ultrasonography in detecting shoulder disease in patients with rheumatoid arthritis. Ann Rheum Dis 2009;68:357-61.
8. Wakefield RJ, D’Agostino MA, Iagnocco A, Filippucci E, Backhaus M, Scheel AK, et al. The OMERACT Ultrasound Group: status of current activities and research directions. J Rheumatol 2007; 34:848-51.

9. D’Agostino MA, Wakefield R, Berner Hammer H, Vittecoq O, Galeazzi M, Balint P, et al. Early response to abatacept plus MTX in MTX-IR RA patients using power Doppler ultrasonography: an open-label study [abstract]. Ann Rheum Dis 2012;71 Suppl 3:186

10. Naredo E, Wakefield RJ, Iagnocco A, Terslev L, Filippucci E, Gandjbakhch F, et al. The OMERACT ultrasound task force-status and perspectives. J Rheumatol 2011;38:2063-7.

11. Bruyn GA. The Swiss musculoskeletal ultrasound recommendations and the SONAR score: do they meet current standards? Swiss Med Wkly 2013;143:w13893.

12. Alcalde M, D’Agostino MA, Bruyn GA, Moller I, Iagnocco A, Wakefield R, et al. A systematic literature review of ultrasound definitions, scoring systems and validity according to the OMERACT filter for tendon lesion in rheumatoid arthritis and other inflammatory joint disease. Rheumatology 2012;51:1246-60.

13. Bruyn GA, Möller I, Garrido J, Bong D, d'Agostino MA, Iagnocco A, et al. Reliability testing of tendon disease using two different scanning methods in patients with rheumatoid arthritis. First step towards an ultrasonography scoring index. Rheumatology 2012;51:1655-61.

14. Naredo E, D'Agostino MA, Wakefield RJ, Moller I, Balint P, Filippucci E, et al. Reliability of a consensus-based ultrasound score for tenosynovitis in rheumatoid arthritis. Ann Rheum Dis 2013;72:1328-34.

15. Bruyn GA, Hanova P, Iagnocco A, d'Agostino MA, Moller I, Terslev L, et al. Ultrasound definition of tendon damage in patients with rheumatoid arthritis. Results of a OMERACT consensus-based ultrasound score and reliability exercise. Ann Rheum Dis 2014;73:1929-34.

16. Terslev L, Gutierrez M, Schmidt WA, Keen HI, Filippucci E, Kane $\mathrm{D}$, et al. Ultrasound as an outcome measure in gout. A validation process by the OMERACT Ultrasound working group. J Rheumatol 2015;42:2177-81.

17. Chowalloor PV, Keen HI. A systematic review of ultrasonography in gout and asymptomatic hyperuricemia. Ann Rheum Dis 2013;72:638-45

18. Gutierrez M, Schmidt WA, Thiele R, Keen H, Kaeley G, Naredo E, et al. International consensus for ultrasound lesions in gout. Results of Delphi process and Web-reliability exercise. Rheumatology (in press).

19. Iagnocco A, Conaghan PG, Aegerter P, Möller I, Bruyn GA, Chary-Valckenaere I, et al. The reliability of musculoskeletal ultrasound in the detection of cartilage abnormalities at the metacarpo-phalangeal joints. Osteoarthritis Cartilage 2012; 20:1142-6

20. Mathiessen A, Haugen IK, Slatkowsky-Christensen B, Bøyesen P, Kvien TK, Hammer HB. Ultrasonographic assessment of osteophytes in 127 patients with hand osteoarthritis: exploring reliability and associations with MRI, radiographs and clinical joint findings. Ann Rheum Dis 2013;72:51-6.

21. Roth J, Jousse-Joulin S, Magni-Manzoni S, Rodriguez A, Tzaribachev N, Iagnocco A, et al. Definitions for the sonographic features of joints in healthy children. Arthritis Care Res 2015;67:136-42

22. Bakewell CJ, Olivieri I, Aydin SZ, Dejaco C, Ikeda K, Gutierrez M, et al. Ultrasound and MRI in the evaluation of psoriatic dactylitis: status and perspectives. J Rheumatol 2013;40:1951-7. 